\title{
Structures and concentrations of surfactants in gut fluid of the marine polychaete Arenicola marina
}

\author{
J. C. Smoot ${ }^{1,3}$, L. M. Mayer ${ }^{2}$, M. J. Bock ${ }^{2,4}$, P. C. $\operatorname{Wood}^{1}$, R. H. Findlay ${ }^{1,5, *}$ \\ ${ }^{1}$ Department of Microbiology, Miami University, Oxford, Ohio 45056, USA \\ ${ }^{2}$ Darling Marine Center, University of Maine, Walpole, Maine 04573, USA \\ ${ }^{3}$ Present address: Department of Civil and Environmental Engineering, University of Washington, Seattle, \\ Washington 98195, USA \\ ${ }^{4}$ Present address: ARCADIS, Portland, Maine 04101, USA \\ ${ }^{5}$ Present address: Department of Biological Sciences, University of Alabama, Tuscaloosa, Alabama 35487, USA
}

\begin{abstract}
Marine invertebrate deposit feeders secrete surfactants into their gut fluid in concentrations sufficient to induce micelle formation, enhancing solubilization of sedimentary lipids. We isolated and identified 3 related surfactant molecules from the deposit-feeding polychaete lugworm Arenicola marina. Surfactants were isolated and separated by a combination of solvent extraction and thin-layer and gas chromatography. Identification was performed using mass and infrared spectrometry, coupled to various derivatization and hydrolysis reactions. A. marina produces a mixture of related yet distinct anionic surfactants composed of branched, C9, saturated and unsaturated fatty acids that are amide linked to leucine or glycine residues, showing some similarity to crustacean surfactants. The critical micelle concentration of the mixture of these surfactants in gut fluid was about $2 \mathrm{mM}$, and total concentrations ranged from 5.5 to $19.5 \mathrm{mM}$. The hydrophilic amide linkage helps to explain previous observations that gut surfactants do not adsorb onto sediment transiting the gut.
\end{abstract}

KEY WORDS: Digestive physiology $\cdot$ Surfactant $\cdot$ CMC $\cdot$ GC-MS $\cdot$ Gut fluid $\cdot$ Sediment

\section{INTRODUCTION}

The digestive fluids of deposit-feeding animals have surface-active agents or surfactants that significantly lower the surface tension of these fluids (Vonk 1969, Mayer et al. 1997, Weston \& Mayer 1998, Smoot \& Findlay 2000, Ahrens et al. 2001). Surfactants are amphiphilic molecules with hydrophobic and hydrophilic ends, which are capable of assembling into molecular aggregates called micelles when the total surfactant concentration reaches a minimum threshold level. This concentration, called the critical micelle concentration $(\mathrm{CMC})$, allows the surfactants to confer new properties to a solution; i.e. in digestive fluids micelles dissolve considerable quantities of otherwise insoluble, hydrophobic compounds of nutritional and toxicological significance. For example, Mayer et al. (1996), Voparil \& Mayer (2000) and Ahrens et al. (2001) showed that surfactants are responsible for enhanced bioavailability of polycyclic aromatic hydrocarbons
(PAH) and halogenated hydrocarbons, respectively, to marine deposit feeders.

Passage through the digestive systems of deposit feeders exposes sediment particles to chemical conditions quite unlike those experienced by these particles elsewhere in the environment. Principal differences between the chemistry of deposit feeder gut fluids and that of sediment interstitial waters include high concentrations of digestive enzymes, surfactants, and dissolved organic matter in the former (Mayer et al. 2001a). Ingestion by selective deposit feeders enriches total organic matter in the gut compared to bulk sediment (Smoot 1999). Deposit feeders appear to minimize nutritional losses to sediment as few, if any, of the introduced digestive agents remain associated with the sediment particles at egestion (Mayer et al. 1997, Smoot \& Findlay 2000). Deposit feeder densities and bioturbation rates imply that the top several centimeters of coastal marine sediments pass through detritivore digestive systems on a time scale of weeks to 
months (Henderson et al. 1999, Green et al. 2002). Combined with the unique chemical milieu, especially the unique presence of surfactant micelles, this processing likely has important impacts on sediment ecology and geochemistry.

While the purpose of surfactants in deposit feeders' guts is not well understood, their common occurrence at concentrations above CMC suggests that micelle formation is critical to gut function. Thus, they likely act to partition food substrates, digestive agents, and hydrolyzates into the fluid phase (Mayer et al. 2001b). The ability of surfactants to influence solubilization depends on the solution composition and their chemical structure. Measurements of critical micelle dilution (CMD, i.e. the point where digestive fluids can no longer maintain reduced contact angles) show that surfactants in deposit feeder digestive fluids are at concentrations typically 5 to 10 times their CMC (e.g. Smoot \& Findlay 2000, Voparil \& Mayer 2000).

Very little is known about surfactant structures in marine benthic invertebrates. Early work showed that crustacean surfactants consisted of dipeptides conjugated to fatty acids (van den Oord et al. 1965). These structures differ greatly from the well-studied, vertebrate, bile-acid surfactants, which generally consist of conjugations of the sterol-like cholic acid and amino acids such as glycine and taurine. To our knowledge, there have been no reports on the surfactants of marine polychaetes, except for a preliminary study suggesting that the surfactant of Aphrodite aculeate has an ester linkage (Vonk 1969). This work sets out to identify the digestive surfactants of Arenicola marina-a common deposit-feeding polychaete found in shallow waters of the North Atlantic-and to measure their $\mathrm{CMC}$, with the aim of gaining insight into their role within detritivore digestive systems.

\section{MATERIALS AND METHODS}

Worm collection and gut fluid isolation. Arenicola marina individuals were collected along the Maine (USA) coast (either Pasamaquoddy Bay or the Sheepscot estuary) using shovels and commercial worm forks, handling them carefully to avoid trauma. To obtain gut fluid, the body wall was opened with a dissecting knife, a clean plastic pipette tip was inserted into the midgut or anterior caecum, and fluid was carefully withdrawn to avoid contamination with body fluids such as blood or coelomic fluid.

Surfactant isolation. Isolation of surfactants from raw gut fluid was accomplished in 3 steps: cold ethanol precipitation of proteins and nucleic acids, dissolution in chloroform with extraction into water, and thin-layer chromatography (Fig. 1). Initial treatment with 90\%

\section{A. marina gut juice}

$90 \%$ cold ethanol precipitation

ethanol soluble fraction

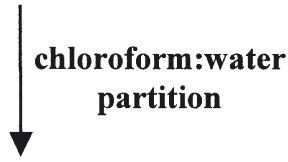

water soluble fraction

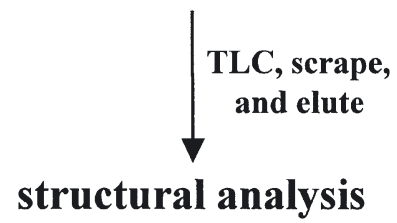

Fig. 1. Arenicola marina. Surfactant isolation scheme used with gut fluid. TLC: thin layer chromatography

cold ethanol and centrifugation $(12000 \times g$ for 5 min) separated the surfactants and other ethanol-soluble compounds from ethanol-insoluble material (Vonk 1962). Ethanol and water were removed by drying under nitrogen at $37^{\circ} \mathrm{C}$. The dried residue was dissolved in chloroform, and an equal volume of water was added. After vortexing, the aqueous phase was collected and dried. The residue was dissolved in chloroform and analyzed with $20 \mathrm{~cm}$, silica-coated, thin layer chromatography (TLC) glass plates until the solvent front migrated $10 \mathrm{~cm}$ past the origin. $\mathrm{R}_{\mathrm{f}} \mathrm{s}$ (retardation factors) were calculated, for all isolated spots, as the ratio of the distance traveled by the compounds to the distance traveled by the solvent front. The TLC mobile phase was 65:25:4 v:v:v dichloromethane:methanol: water. The surfactants produced a distinctive, irregular spot at $\mathrm{R}_{\mathrm{f}}=0.85$, that was visualized by backlighting the TLC plate with a light box. The surfactants were eluted from the silica with 10 column volumes of the mobile phase solvent system and analyzed by gas chromatography (GC) and mass spectrometry (MS) on an HP 5890 fitted with a 30 m DB5-MS column (J\&W Scientific) and an HP 5972 mass-selective detector.

Monitoring surfactant activity during isolation. The presence of surfactants after each step of the isolation process was monitored by measuring the contact angle of aqueous drops on a parafilm surface (Mayer et al. 1997). By progressively diluting these drops, we determined the level of dilution of gut fluid necessary to eliminate micelle formation. This dilution, expressed as percentage of original concentration, is termed the CMD factor, and provides a measure of relative concentrations of surfactants. Aqueous solutions of test 
fractions were made with deionized water plus 3.5\% Instant Ocean seasalt (Aquarium Systems) to maintain the original volume and approximate salinity of the original gut fluid. CMD was determined by indicator variable regression analyses, which detects the breakpoint between 2 regression lines (see Fig. 2 for example). Calculations of the test statistic used to compare regression slopes $\left[F^{*}=\operatorname{SSR}\left(X_{1} X_{2} \mid X_{1}, X_{2}\right) / 1 \div\right.$ $\operatorname{SSE}\left(X_{1}, X_{2}, X_{1}, X_{2}\right) / \mathrm{n}-4$; Neter et al. 1996] were done with Minitab 12.

Molecular derivatization. The surfactants were chemically treated to elucidate their chemical structures, determine the presence of functional groups, and improve mobilization of the compounds by gas chromatography. Methylation of native surfactants was done with concentrated hydrochloric acid:chloroform:methanol $(1: 1: 9 \mathrm{v}: \mathrm{v}: \mathrm{v})$ for $1 \mathrm{~h}$ at $100^{\circ} \mathrm{C}$. After cooling to room temperature, the reaction mixture was partitioned with equal volumes of chloroform and deionized water and centrifuged for $10 \mathrm{~min}$ at $1500 \times \mathrm{g}$. The organic phase and two $1 \mathrm{ml}$ chloroform washes were combined. Samples were dried with nitrogen at $37^{\circ} \mathrm{C}$ and suspended in chloroform. Treatment of samples with pyridine: bis(trimethylsilyl)trifluoroacetamide, BSTFA, (2:1 v:v) at $100^{\circ} \mathrm{C}$ for $1 \mathrm{~h}$ as described by the manufacturer (Supelco), produced trimethylsilyl (TMS) derivatives of the surfactant molecules. TMS derivatives were recovered

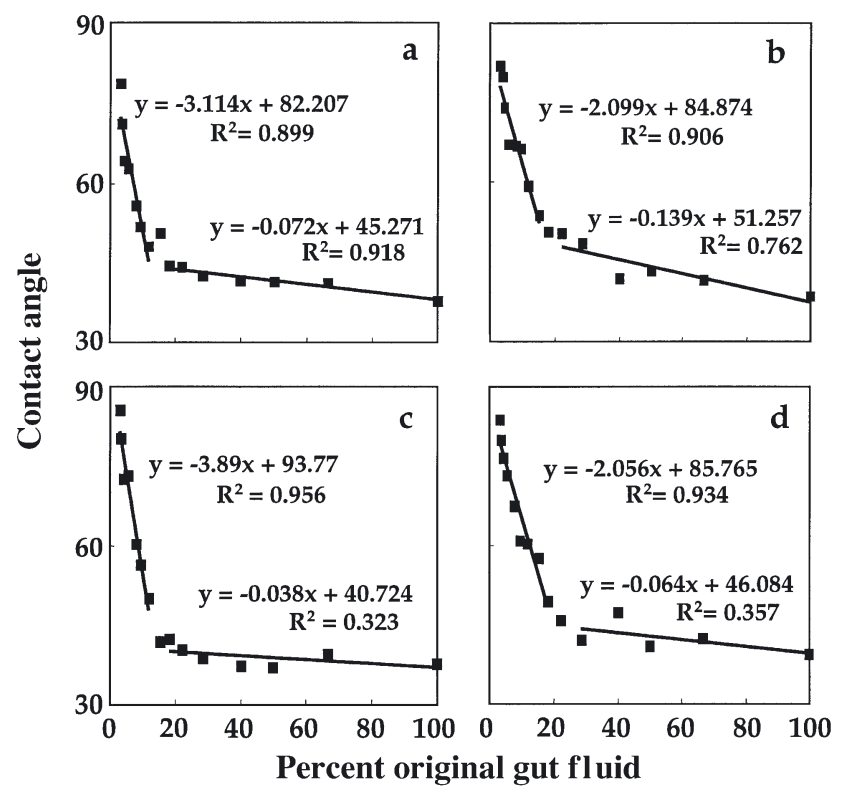

Fig. 2. Arenicola marina. Determination of surfactant critical micelle dilution (CMD) of surfactant at various stages during the isolation scheme by measurement of contact angle on parafilm. (a) Raw gut fluid, (b) ethanol soluble fraction, (c) water soluble fraction and (d) material eluted from the thin layer chromatography (TLC) plate. Points represent the mean, plotted for clarity of presentation, of 3 independent measures of contact angle. Statistical analyses were run using replicate measures of contact angle in hexane partitioned against $0.2 \mathrm{~N}$ acetic acid $(1: 1 \mathrm{v}: \mathrm{v})$. Alkaline methylation reactions were done as described previously (Findlay 1996). Briefly, samples were exposed to $0.2 \mathrm{~N}$ methanolic potassium hydroxide with 1:1 (v:v) toluene-methanol for $15 \mathrm{~min}$ at $37^{\circ} \mathrm{C}$. The reaction was terminated with $0.2 \mathrm{~N}$ acetic acid and equal volumes of water and chloroform.

Hydrolysis of the surfactants into their amino acid and fatty acid components was done under acidic conditions. Samples were treated overnight with $6 \mathrm{~N} \mathrm{HCl}$ at $110^{\circ} \mathrm{C}$. The fatty acid and amino acid components were recovered by partitioning the samples with chloroform. Free fatty acids were methylated using the previously described acid methylation and BSTFA techniques, except after derivatization, samples were dried under nitrogen without heat to prevent loss of the semi-volatile products. Dimethyl disulfide was used to determine the double-bond position of the unsaturated fatty acid using the methods of Nichols et al. (1986), except the reaction took place at $50^{\circ} \mathrm{C}$ for $64 \mathrm{~h}$. After the reaction was complete, samples were partitioned with hexane:5\% sodium thiosulfate $(1: 1 \mathrm{v}: \mathrm{v})$ and recovered in hexane with 2 hexane:chloroform $(4: 1 \mathrm{v}: \mathrm{v})$ washes. Amino acids collected from the aqueous fraction were modified for GC-MS identification using the techniques described previously (Barancin et al. 1998, Sonesson et al. 1988). Briefly, the aqueous fraction was frozen at $-80^{\circ} \mathrm{C}$ and lyophilized. Residual water was removed by drying with methanol followed by drying with dichloromethane. Samples were butylated under acidic conditions $(4: 1 \mathrm{v}: \mathrm{v}$ butanol:concentrated $\mathrm{HCl})$ at $120^{\circ} \mathrm{C}$ for $20 \mathrm{~min}$. The recovered butyl esters were dissolved in $100 \mu \mathrm{l}$ heptafluorobutyric acid anhydride for $2 \mathrm{~min}$, and $100 \mu \mathrm{l}$ ethyl acetate was added. The samples were held at $150^{\circ} \mathrm{C}$ for $12 \mathrm{~min}$ and immediately transferred to an ice water bath. Derivatives were recovered in the organic phase after partitioning with ethyl acetate: phosphate buffered saline $(1: 1 \mathrm{v}: \mathrm{v})$ followed by hexane:0.2 $\mathrm{N}$ acetic acid $(2: 1 \mathrm{v}: \mathrm{v})$.

Standards. Analytical quantities of 2,6-dimethylheptanoic acid were synthesized to verify the structure of the saturated fatty acid moiety of the surfactants by oxidizing pristane with potassium permanganate, as described by Murray (1959), except that the solution was heated at $100^{\circ} \mathrm{C}$ until the solution was no longer purple, the acetone was evaporated, $1 \mathrm{M}$ sodium sulfite and $4 \mathrm{ml} 2 \mathrm{~N} \mathrm{HCl}$ were added to dissolve the precipitate, and the solution was partitioned and washed twice with ethyl ether. Fatty acids were methylated as described for the surfactant identification. The manufacturer Matreya synthesized 2,6-dimethylheptanoic acid, which was, in turn, used in the custom synthesis of surfactant molecules by Bio-Synthesis. Authentic amino acid standards were purchased from Sigma. Standards were modified for GC-MS analysis using 
the same protocols described for the surfactant identification.

Quantification of surfactants, CMD and CMC calculations. Gut fluid from 4 individual worms and 2 composite samples each representing 100 worms was fractionated to verify that the surface activity was associated with the characterized surfactants and to determine the CMC of the surfactants. The gut fluids from the 4 worms varied in that they either included or were void of sediment and were either light or dark in color. For each of these samples, subsamples were removed after each step of the procedure. GC analysis and contact angle measurements were carried out to quantify the components of each fraction and to measure the CMD, respectively, of raw gut fluid and various isolation fractions. A sample of the ethanol fraction of gut fluid was analyzed with GC before and after methylation to determine the response factors of native surfactants. The response factors for the N-acyl leucinate and N-acyl glycinate surfactants were 1.8 and 2.5, respectively. Saturated and polyenoic ethylester fatty acid standards (Supelco) were added to samples prior to GC analysis to determine the mass of the surfactants by assuming an equal mass response. Molar concentrations of the surfactants were calculated with the response factors, molecular weights from GC-MS analysis, and fraction volumes. CMCs of the mixture of surfactants were calculated based on the sum of the individual surfactants and the measured CMD from the matched aliquot for each fraction.

\section{RESULTS}

\section{Surfactant isolation}

Arenicola marina gut-fluid surfactants were isolated as a mixture of related compounds in 3 steps, and further separated with GC (Fig. 1). Addition of ethanol to gut fluid produced a precipitate and a colored ethanol extract. CMD measurements showed that the surfactants partitioned to the ethanol extract (Fig. 2). Addition of water to the ethanol extract which was dissolved in chloroform partitioned the surfactants to the aqueous phase, while the lipids remained dissolved in the chloroform. One spot recovered from TLC of the aqueous soluble fraction produced a CMD equivalent to raw gut fluid (Fig. 2). The contents of the surface active TLC spot were separated into 4 major components and several minor components with GC; all putative surfactant molecules are shown in Fig. 3. GC-MS analysis of the surface active TLC spot indicated that the 3 most abundant components (Am1, Am2, and Am3) had a saturated or monoenoic hydrocarbon component and a component that readily lost water when ionized. Fig. 3 shows that the native form of Am2 elutes as 2 peaks during GC analysis. The primary peak and shoulder have identical mass spectra and coeluted as 1 peak after methylation, suggesting that they are an isomeric mixture in gut micelles. Minor components of the surface active TLC spot had mass spectra similar to Am1, Am2, and Am3 but varied by carbon chain lengths. The 4th major component (not shown) eluted very early in the GC run, was semivolatile, and was recovered in varying amounts depending on sample preparation. GC-MS analysis indicated that this component consisted of at least one branched fatty alcohol (but may be a mixture of several chain lengths) and may serve as a cosurfactant.

\section{Structural identification of Arenicola marina gut-fluid surfactants}

A combination of GC-MS, GC-IR (gas chromatography-infrared), chemical derivatization, and standards were used to identify the structures of Am1, Am2, and Am3. GC-MS analysis suggested that the molecular weights of Am1, Am2, and Am3 were 215, 271 and 269, respectively. Water is produced as a neutral leaving group during ionization of the native molecules and accounts for the 18 atomic mass unit (amu) difference between the molecular weight and $\mathrm{M}^{+}$ion in the spectra of the native surfactants (Fig. 4). The progressive decrease in a mass-spectral ion-fragment series by $14 \mathrm{amu}$ indicated that all 3 molecules contained at least 1 chain of 7

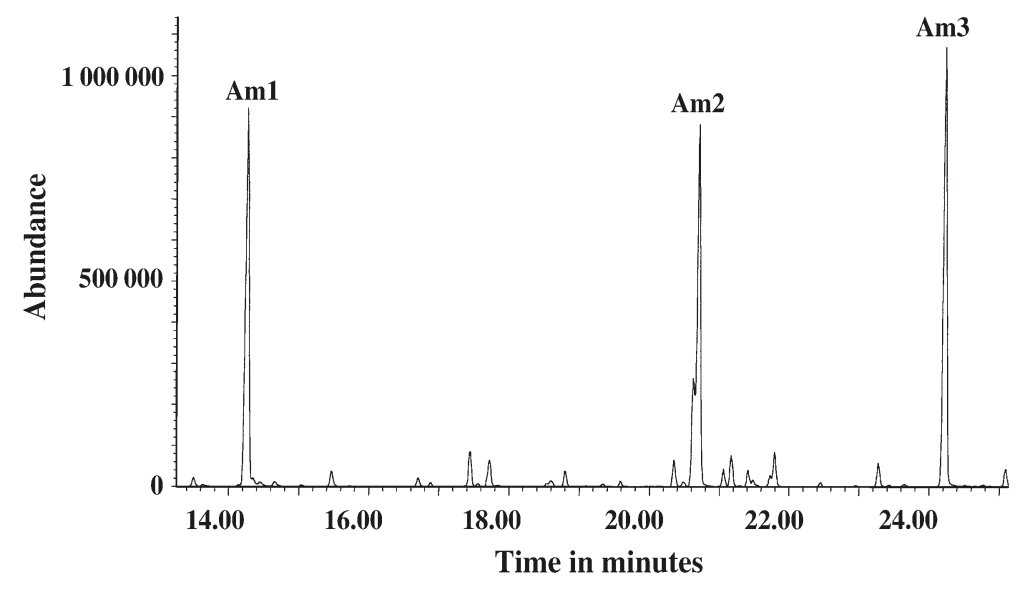

Fig. 3. Arenicola marina. Gas chromatography and mass spectrometry (GC-MS) total ion trace of the surface-active TLC spot of gut fluid. The trace is of the native surfactants prior to derivatization. The surfactants that coeluted with TLC separated with GC analysis into several structurally distinct molecules. The main surfactants were identified as Am1, Am2 and Am3 

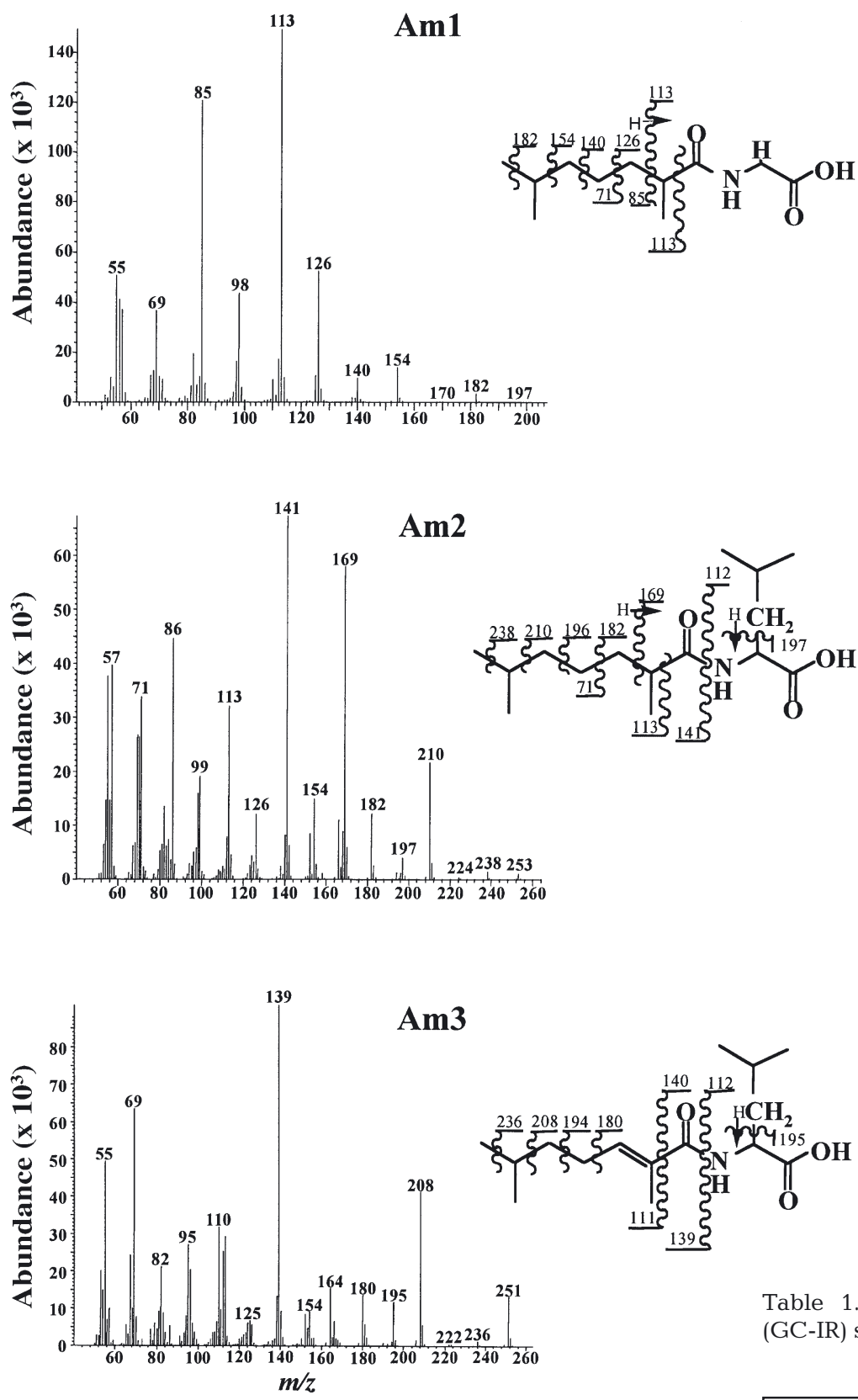

Fig. 4. Arenicola marina. Mass spectra and fragment analysis of Am1, Am2, and Am3. The spectra of the native surfactants prior to derivatization are shown. The inset shows the fragment analysis superimposed on the structural diagrams of the molecules. Numbers in the diagram correspond to the atomic mass units of the fragments in the mass spectra. $\mathrm{m} / \mathrm{z}$ : mass to charge ratio

carbons (Fig. 4). The odd numbered $\mathrm{M}^{+}$ion and base ions suggested that the molecules contained an odd number of nitrogen atoms (McLafferty \& Turecek 1993). The difference of 2 amu between Am2 and Am3 suggested the presence of an unsaturated aliphatic chain in Am3. GCIR analysis of the methylated forms of Am1, Am2, and
Am3 suggested that the compounds had 2 carbonyl carbons (Table 1). In addition, GC-IR analysis indicated the presence of a secondary amine, tertiary amine, or amide group. GC-IR also indicated the presence of methyl carbons in Am1, Am2, and Am3, and an infrared absorbance at $1643 \mathrm{~cm}^{-1}$ indicated a carbon-carbon double bond in Am3 (Table 1). Chemical derivatization of Am1, Am2, and Am3 with methanol and BSTFA indicated that one of the carbonyl carbons identified by GC-IR analysis was part of a carboxyl group. Two factors indicated that the carboxyl group in each compound was a free acid rather than an ester. First, the methyl and BSTFA derivatives of Am1, Am2, and Am3 increased by 32 and 90 amu compared to mass spectra of the native compounds, indicating a stabilization of the carboxyl group and replacement of a hydrogen with a methyl or trimethylsilyl group, respectively. Second, methylation of the 3 compounds only occurred under acidic conditions. The previously mentioned production of water as a neutral leaving group during ionization of the native molecules is also consistent with the presence of a carboxyl group. Attempts to chemically modify the nitrogen group (using BSTFA and acetic anhydride ) in Am1, Am2, and Am3 failed (data not shown). The presence of a carbonyl group in addition to the carboxylic carbonyl carbon and a non-reactive secondary nitrogen group suggested the presence of an amide bond in the molecules.

Am1, Am2, and Am3 were hydrolyzed under acidic conditions to test the hypothe-

Table 1. Arenicola marina. Gas chromatography-infrared (GC-IR) spectral peaks of the methylated forms of Am1, Am2, and Am3

\begin{tabular}{|lcc|}
\hline Molecule ID & $\begin{array}{r}\text { Wave number } \\
\left(\mathrm{cm}^{-1}\right)\end{array}$ & $\begin{array}{c}\text { Functional } \\
\text { group(s) }\end{array}$ \\
\hline Am1 & 1709 & Carbonyl carbon \\
Am1 & 1756 & Carbonyl carbon \\
Am1 & 2964 & Methyl carbons \\
Am1 & 3457 & 2 or 3 $3^{\circ}$ amine, amide \\
Am2 & 1704 & Carbonyl carbon \\
Am2 & 1756 & Carbonyl carbon \\
Am2 & 2964 & Methyl carbons \\
Am2 & 3446 & 2 or 3 amine, amide \\
Am3 & 1643 & Carbon-carbon double bond \\
Am3 & 1691 & Carbonyl carbon \\
Am3 & 1756 & Carbonyl carbon \\
Am3 & 2964 & Methyl carbons \\
Am3 & 3455 & 2 or 3 $3^{\circ}$ amine, amide \\
\hline
\end{tabular}


Table 2. Arenicola marina. Base- and mass ions of the fatty acid components of Am1, Am2, and Am3 after acid hydrolysis of the surfactants. FFA: free fatty acid; FAME: fatty acid methylester; TMS: trimethylsilylester; $\mathrm{m} / \mathrm{z}$ : mass to charge ratio

\begin{tabular}{|cc|}
\hline Derivative & Mass spectral ions $(\mathrm{m} / \mathrm{z})$ \\
\hline & $\frac{2,6 \text {-dimethylheptanoic acid }}{74 / 158}$ \\
FFA & $88 / 172$ \\
FAME & $73 / 230$ \\
TMS & 2,6-dimethylheptenoic acid \\
& 101/156 \\
FFA & $213 / 228$ \\
FAME & \\
TMS
\end{tabular}

sis that the compounds contained an amide bond. The acid hydrolysate was partitioned so that the hydrophobic and hydrophilic components of the compounds could be characterized. The chloroform-soluble fraction of the hydrolysate contained a C9 saturated fatty acid and a C9 monoenoic fatty acid. The increased abundance of 88 and 101 amu base ions in the fatty acid methylester derivatives, the lack of a $143 \mathrm{amu}$ fragment in the spectra of the fatty acid methyl esters (Douglas et al. 1971), and the agreement between free fatty acid and derivative spectra suggested that the fatty acids were 2,6-dimethylheptenoic acid and 2,6-dimethylheptanoic acid (Table 2). To verify the structure of the 2,6-dimethylheptanoic acid, pristane was oxidized with potassium permanganate. Oxidation of pristane produces a mixture of products including 2,6-dimethylheptanoic acid (Rowland et al. 1984). The methylated products of the pristane oxidation included a compound that had the same retention time and mass spectrum as the methylated form of the saturated fatty acid produced after hydrolysis of the surfactants, and thus corroborated the aliphatic tail of Am1 and Am2. The amino acids glycine and leucine in the aqueous fraction of the hydrolysate were identified with GC-MS analysis, and confirmed by comparison of GC retention times and mass spectra of samples and authentic standards.

Taken together, the data indicated that Am1 has a 2,6-dimethylheptanoic acid amide linked to glycine, Am2 has a 2,6-dimethylheptanoic acid amide linked to a leucine, and Am3 has 2,6dimethylheptenoic acid amide linked to a leucine (Fig. 4). Comparison of GC retention times and mass spectra for $\mathrm{Am} 1$ and Am2 with authentic standards confirmed their structures. Mass spectral analysis of dimethyl disulfide derivatives placed the double bond in Am3 between the second and third carbons of the 2,6-dimethylheptenoic acid (data not shown). The position of the double bond was not confirmed with an authentic standard.

\section{Quantification of Arenicola marina gut fluid surfactant CMCs}

Surfactant molecules Am1, Am2, and Am3 were isolated from gut fluid taken from 4 individual worms and from 2 composite gut fluid samples, each representing 100 individual worms. Surfactant concentrations and CMD values of different fractions of gut fluid, reconstituted to original gut fluid volumes, from individual worms and composite samples of gut fluid did not significantly vary among fractions, although there was a trend toward decreasing concentrations and subsequent increasing CMDs during the isolation process (Fig. 2). Other fractions collected during isolation (e.g. the chloroform fraction of the aqueous-chloroform partition and a smear of amino acids isolated with TLC) produced higher contact angles, ranging from 61.6 to $102.3^{\circ}$, and thus did not show surfactant activity.

Because individual CMC values cannot be calculated from the mixture of gut fluid surfactants, a mixed micelle CMC was determined. Molar ratios of Am1, Am2 and Am3 were 1:2:2 in the composite gut fluid samples and were similar to the molar ratios of the surfactants observed in the gut fluid of individual worms. The combined concentrations of Am1, Am2, and Am3 in ethanol extracts of Arenicola marina gut fluid ranged from 5.5 to $19.5 \mathrm{mM}$ (Table 3). The CMD values for the gut fluid ranged from 12 to $22 \%$ of original gut fluid. The CMCs of the surfactants in mixed micelles from the ethanol fraction ranged from 1.2 to $4.0 \mathrm{mM}$. Given the large variance in digestive agent concentrations that are normally found within species in deposit feeder gut fluids (Mayer et al. 1997), these concentrations are all rather similar to each other and to the concentrations measured in the composite gut fluid samples.

Table 3. Arenicola marina. Concentration of surfactants and mixed micelle critical micelle concentrations (CMC) of individual and composite gut fluid samples. CMD: critical micelle dilution; values are ethanol-soluble fraction of gut fluid and raw gut fluid (values in parentheses)

\begin{tabular}{|lccccrc|}
\hline Sample & $\begin{array}{c}\text { Sediment } \\
\text { in gut }\end{array}$ & Color & $\begin{array}{c}\text { Concentration } \\
(\mathrm{mM})\end{array}$ & CMD (\%) & $\begin{array}{r}\text { CMC } \\
(\mathrm{mM})\end{array}$ \\
\hline Worm 1 & Present & Light & 16.2 & 11.8 & $(9.5)$ & 1.9 \\
Worm 2 & Absent & Light & 15.3 & 11.8 & $(11.8)$ & 1.8 \\
Worm 3 & Present & Light & 15.1 & 18.2 & $(18.2)$ & 2.8 \\
Worm 4 & Present & Dark & 5.5 & 22.2 & $(28.6)$ & 1.2 \\
Composite 1 & Present & & 19.5 & 11.8 & $(18.2)$ & 2.3 \\
Composite 2 & Absent & & 17.9 & 22.2 & $(22.2)$ & 4.0 \\
\hline
\end{tabular}




\section{DISCUSSION}

We identified a complex mixture of surfactants from the gut fluid of Arenicola marina. These molecules likely form mixed micelles in the gut. The A. marina surfactants possess structurally unique fatty acid tails compared to other characterized surfactants. The branched fatty acid chains of these molecules are short compared to commercial and other biological surfactants. However, the presence of hydrophobic amino acids in Am2 and Am3 increases their hydrophobicity, and results in branched surfactants that have 2 hydrophobic tails capable of folding back on themselves to produce the hydrophobic core of micelles (Evans 1956, Funasaki \& Hada 1978). Methyl branches in the fatty acids disrupt chain stacking of the tails, and therefore may decrease the molecular associations among fatty acid chains in the core of the micelles. The relatively short and branched hydrophobic components of these surfactants are notable and may relate to toxicity. Surfactants with longer hydrophobic moieties are often more toxic than surfactants with shorter ones (Versteeg et al. 1997). Thus, the unique molecular features of the fatty acid chains may reduce self-damage within the digestive tract while providing an effective means of dissolving a potentially diverse assemblage of hydrophobic molecules.

The amide bond in the surfactants is central to both the structure of the surfactants and their chemical properties, and may be particularly well-suited for use by poikilothermic invertebrates living in marine sediments. Amide bonds make surfactants relatively insensitive to precipitation caused by dissolved calcium and by low temperatures (Mizushima et al. 1999). Amide bonds increase hydrogen bonding between surfactant and water molecules, which increases the solubility of the surfactants in their monomer (non-micelle) state. Recent adsorption experiments showed that Arenicola marina gut fluid surfactants do not adsorb to unpolluted sediment (Mayer et al. 2001b), which is a desirable feature for digestive agents in deposit feeders. The increased hydrophilicity of the amide bond, relative to other potential linkages, likely contributes to the lack of surfactant adsorption, as has been found for other surfactant systems (Kjellin et al. 2002). Thus the amide bond may provide a mechanism for retaining the surfactants in the gut fluid while minimizing their loss to consumed sediment. In addition, amide bonds promote surfactant micelle formation.

The CMCs of surfactants with amide bonds are lower than the CMCs of structurally related compounds that do not have an amide bond (Infante \& Moses 1994, Mizushima et al. 1999, Folmer et al. 2001). The role of the amide bond in micelle formation is unclear. Mizushima et al. (1999) proposed that the amide bond increases the depth of the polar-head group of N-alkyl amide sulfates compared to alkyl sulfates, while Folmer et al. (2001) conclude that hydrogen bonding associated with the amide bond drives micelle formation. It is likely that a combination of these features, depending on the amino acid side chain and bond rotation about the $\alpha$-carbons, influences micelle formation. The gut fluid CMC of the surfactants is influenced by both their chemical structures and the gut fluid chemistry. For instance, the CMCs of N-acyl amino-acid surfactants, surfactants that are structurally related to the Arenicola marina surfactants, vary based on fatty acid length and amino-acid side chain. Shortening the fatty acid moiety in this group of surfactants by 2 methylene groups increases the CMC 4-fold (Miyagishi \& Nishida 1978). Differences in the $\mathrm{N}$-acyl amino-acid side chain have a similar but subtler effect on CMC. For example, sodium lauroylvalinate has a CMC half that of sodium lauroylglycinate (Miyagishi et al. 1985). The CMCs of the A. marina surfactants fall at the low end of the 1 to $20 \mathrm{mM}$ range typical of bile salts in vertebrate systems (Small 1971). These low $\mathrm{CMC}$ values for the $A$. marina gut fluid surfactants may be partially due to the influence of solution chemistry on the CMC of the surfactants. For instance, the $\mathrm{CMC}$ of sodium lauroylleucinate decreases an order of magnitude when the salt concentration is increased from 0.01 to $1.0 \mathrm{M}$ (Miyagishi et al. 1996). The CMC of the potassium salt of decanoylsarcosyltaurine decreased nearly 3 -fold in the presence of $0.15 \mathrm{M}$ sodium phosphate buffer and $0.02 \mathrm{M}$ calcium chloride (Vonk 1969). Assuming the gut fluid salinity of A. marina is approximately equivalent to seawater (as suggested by the data of Chen et al. 2001), the observed CMC of $2 \mathrm{mM}$ is reasonable. In addition, surfactants present in mixed surfactant systems have lower CMCs than when they are present in a homogeneous solution (Miyagishi et al. 1985).

The structures of digestive surfactants vary phylogenetically but possess physiochemically similar properties. The Cancer pagurus digestive surfactant and the digestive surfactants of Arenicola marina are structurally similar, in that they both contain a fatty acid residue and at least 1 amide-bonded amino acid residue. Vertebrate digestive surfactants also include amino acids, but they are conjugated to cholesterol derivatives rather than fatty acids. Herbivorous insects use lysolecithin, a zwitterionic monoacyl phospholipid, as a digestive surfactant (Turunen \& Kastari 1979). The water beetle Dytiscus marginalis and echinoderm Holothuria tubulosa appear to produce surfactants that contain a sulfate group (Vonk 1969). The echinoderm Parastichopus californicus produces a digestive surfactant that shares physiochemical properties with the A. marina digestive surfactants, in that it is effectively 
isolated and purified by our protocol. It produced a similar but distinct GC trace and mass spectra, but remains unidentified (J. C. Smoot \& R. H. Findlay unpubl. data). The convergent evolution of these molecules points to the fundamental physiological requirement to produce surfactants during digestion. Transport of insoluble lipids from the sedimentary matrix to the gut wall is one of several potential proximal causes of this physiological requirement.

Digestive surface activity is linked to animal feeding strategies. Deposit-feeding marine invertebrates have low digestive surfactant CMDs, reflecting higher surfactant concentrations compared to benthic invertebrates that feed as carnivores (Mayer et al. 1997). Nereis virens, an omnivore, has lower surfactant CMDs when it feeds on sediment compared to when it feeds as a carnivore (Bock \& Mayer 1999). Dorosoma cepedianum, a freshwater fish, has lower CMDs when feeding on sediment as an adult compared to when it carnivorously feeds as a larvae (Smoot \& Findlay 2000). The presence of surfactant in Arenicola marina gut fluid may reflect its sediment-rich diet. Mayer et al. (1997) proposed a multifunctional role for surfactants in deposit feeders, including reduction in adsorption of digestive enzymes to sediment. Herbivorous insects produce surfactants to counter tannins that precipitate digestive enzymes (Martin \& Martin 1984, Martin et al. 1985). Similarly, the surfactants of $A$. marina might prevent humic compounds associated with sediment from precipitating digestive enzymes.

Molecular identification of the gut fluid surfactants allows a more refined physiochemical characterization of digestive processes and their influence on nutritional and pollutant lipid solubilization. Coupling surfactant and other gut chemistry measurements (e.g. dissolved amino acids, protein, $\mathrm{pH}$, and ionic strength) with gut reactor models will enhance in vivo lipid dissolution models. A mass balance of production, turnover, and loss of the gut fluid surfactants by measuring both solid- and liquid-phase concentrations of the surfactant and fatty acid moieties will provide insights into the digestive physiology of deposit feeding and other feeding strategies. In addition, it is now possible to determine the effects of cosurfactants on the surfactant CMC and to measure the in vitro and in vivo $\mathrm{PAH}$ solubilization capacity of the surfactants. The identification and characterization of surfactants from other marine invertebrates will also enhance the modeling of digestive mobilization of pollutants.

Feeding strategy defines the position of metazoans within food webs and is a source of species richness and niche diversification within marine systems. Characterization of the digestive milieu of deposit-feeding organisms is necessary to further our understanding of the ecology of benthic systems. We have elucidated the structures of gut surfactants in a marine polychaete. These structures are consistent with the physiological ecology of deposit feeding, which should favor surfactants that are: (1) non-adsorptive onto transiting sediment, (2) non-denaturing to dissolved proteins that provide digestive enzyme activity, (3) non-toxic to gut tissues, and (4) stably dissolved in divalent ion-rich seawater. The evolution of surfactants with the above properties was likely central to the success of this diverse trophic group. Unfortunately, the presence of surfactants at concentrations above CMC also confers a susceptibility to lipophilic pollution, such as PAH or halogenated hydrocarbons, and an anthropogenic impact on deposit-feeding organisms may adversely affect the trophodynamics and nutrient cycling within ecosystems.

Acknowledgements. We thank P. A. McGinn for technical assistance and the Ohio State University Analytical Spectroscopy Laboratory which performed the GC-IR analysis (we take full responsibility for the interpretation of spectra). We thank Dr. L. M. Smoot for critical review of the manuscript and I. Voparil for discussions. This work was supported by the Office of Naval Research, the National Science Foundation (OCE 9618552) and the Army Corps of Engineers. It is contribution no. 381 from the Darling Marine Center.

\section{LITERATURE CITED}

Ahrens MJ, Hertz J, Lamoureux EM, Lopez GR, McElroy AE, Brownawell BJ (2001) The effect of body size on digestive chemistry and absorption efficiencies of food and sediment-bound organic contaminants in Nereis succinea (Polychaeta). J Exp Mar Biol Ecol 263:185-209

Barancin CE, Smoot JC, Findlay RH, Actis LA (1998) Plasmidmediated histamine biosynthesis in the bacterial fish pathogen Vibrio anguillarum. Plasmid 39:235-244

Bock MJ, Mayer LM (1999) Digestive plasticity of the marine benthic omnivore Nereis virens. J Exp Mar Biol Ecol 240: $77-92$

Chen Z, Mayer LM, Quétel C, Donard OFX, Self RFL, Jumars PA, Weston DP (2000) High concentrations of complexed metals in the guts of deposit feeders. Limnol Oceanogr 45: 1358-1367

Douglas AG, Blumer M, Eglinton G, Douraghi-Zadeh K (1971) Gas chromatographic-mass spectrometric characterization of naturally-occurring acyclic isoprenoid carboxylic acids. Tetrahedron 27:1071-1092

Evans HC (1956) Alkyl sulfates: critical micelle concentrations of the sodium salts. J Chem Soc 579-586

Findlay RH (1996) The use of phospholipid fatty acids to determine microbial community structure. In: Akkermans DL, Van Elsas JD, deBruijn FJ (eds) Molecular microbial ecology manual. Kluwer Academic Publishers, Norwell, MA, p 4.1/1-4.1.4/17

Folmer BM, Holmberg K, Klingskog EG, Bergström K (2001) Fatty amide ethoxylates: synthesis and self-assembly. J Surfact Deterg 4:175-183

Funasaki N, Hada S (1978) Two alkyl chains of sulfoxides in water; intermolecular association. J Colloid Interface Sci 64:454-460 
Green MA, Aller RC, Cochran JK, Lee C, Aller JY (2002) Bioturbation in shelf/slope sediments off Cape Hatteras, North Carolina: the use of Th-234, Ch1-a, and Br- to evaluate rates of particle and solute transport. Deep-Sea Res Part II 49:4627-4644

Henderson GM, Lindsay FN, Slowey NC (1999) Variation in bioturbation with water depth on marine slopes: a study on the Little Bahamas Bank. Mar Geol 160:105-188

Infante MR, Moses V (1994) Synthesis and surface activity properties of hydrophobic/hydrophilic peptides. Int $\mathrm{J}$ Peptide Protein Res 43:173-179

Kjellin UR, Claesson PM, Linse P (2002) Surface properties of tetra(ethylene oxide) dodecyl amide compared with poly(ethylene oxide) surfactants. 1. Effect of the headgroup on adsorption. Langmuir 18:6745-6753

Martin MM, Martin JS (1984) Surfactants: their role in preventing the precipitation of proteins by tannins in insect guts. Oecologia 61:342-345

Martin MM, Rockholm DC, Martin JS (1985) Effects of surfactants, $\mathrm{pH}$, and certain cations on precipitation of proteins by tannins. J Chem Ecol 11:485-494

Mayer LM, Chen Z, Findlay RH, Fang JS and 5 others (1996) Bioavailability of sedimentary contaminants subject to deposit-feeder digestion. Environ Sci Technol 30: 2641-2645

Mayer LM, Schick LL, Self RFL, Jumars PA, Findlay RH, Chen Z, Sampson S (1997) Digestive environments of benthic macroinvertebrate guts: enzymes, surfactants, and dissolved organic matter. J Mar Res 55:785-812

Mayer LM, Weston DP, Bock MJ (2001a) Benzo-a-pyrene and zinc solubilization by digestive fluids of benthic invertebrates - a cross-phyletic study. Environ Toxicol Chem 20: 1890-1900

Mayer LM, Jumars PA, Bock MJ, Vetter YA, Schmidt JL (2001b) Two roads to sparagmos: extracellular digestion of sedimentary food by bacterial inoculation verses deposit feeding. In: Aller JY, Woodin SA, Aller RC (eds) Organism-sediment interactions. University of South Carolina Press, Columbia, p 335-347

McLafferty FW, Turecek F (1993) Interpretation of mass spectra. University Science Books, Mill Valley, CA

Miyagishi S, Nishida M (1978) Influence of chirality on micelle formation of sodium $\mathrm{N}$-acylalanates and sodium N-lauroylvalinates. J Colloid Interface Sci 65:380-386

Miyagishi S, Ishibai Y, Asakawa T, Nishida M (1985) Critical micelle concentration in mixtures of $\mathrm{N}$-acyl amino acid surfactants. J Colloid Interface Sci 103:164-169

Miyagishi S, Akasohu W, Hashimoto T, Asakawa T (1996) Effect of $\mathrm{NaCl}$ on aggregation number, microviscosity and CMC of N-dodecanoyl amino acid surfactant micelles. J Colloid Interface Sci 184:527-534

Mizushima H, Matsuo T, Satoh N, Hoffmann H, Graebner D (1999) Synthesis and properties of N-alkyl amide sulfates. Langmuir 15:6664-6670

Editorial responsibility: Otto Kinne (Editor), Oldendorf/Luhe, Germany
Murray KE (1959) A method for the determination of the structure of saturated branched-chain fatty acids. Aust J Chem 12:657-670

Neter J, Kutner MH, Nachtsheim CJ, Wasserman W (1996) Applied linear statistical models. Irwin, Chicago

Nichols PD, Guckert JB, White DC (1986) Determination of monounsaturated fatty acid double-bond position and geometry for microbial monocultures and complex consortia by capillary GC-MS of their dimethyl disulphide adducts. J Microbiol Methods 5:49-55

Rowland SJ, Larcher AV, Alexander R, Kagi RI (1984) Gas chromatography and gas chromatography-mass spectrometry analysis of diastereomeric acyclic isoprenoid esters using fused-silica capillary columns. J Chromatogr 312:395-402

Small DM (1971) The physical chemistry of cholanic acids. In: Nair PP, Kritchevsky D (eds) The bile acids, Vol 1. Plenum Press, New York, p 249-356

Smoot JC (1999) A field study of sedimentary microbiota as food for detritivorous gizzard shad, Dorosoma cepedianum, in Acton Lake: a biomarker approach. PhD dissertation, Miami University, Oxford, $\mathrm{OH}$

Smoot JC, Findlay RH (2000) Digestive enzyme and gut surfactant activity of detritivorous gizzard shad. Can J Fish Aquat Sci 57:1113-1119

Sonesson A, Larsson L, Fox A, Westerdahl G, Odham G (1988) Determination of environmental levels of peptidoglycan and lipopolysaccharides using gas chromatography with negative-ion chemical-ionization mass spectrometry utilizing bacterial amino acids and hydroxy fatty acids as biomarkers. J Chromatogr 431:1-15

Turunen S, Kastari T (1979) Digestion and absorption of lecithin in larvae of the cabbage butterfly, Pieris brassicae. Comp Biochem Physiol 62A:933-937

van den Oord A, Danielsson H, Ryhage R (1965) On the structure of the emulsifiers in gastric juice from the crab, Cancer pagurus L. J Biol Chem 240:2242-2247

Versteeg DJ, Stanton DT, Pence MA, Cowan C (1997) Effects of surfactants on the rotifer, Brachionus calyciflorus, in a chronic toxicity test and in the development of QSARs. Environ Toxicol Chem 16:1051-1058

Vonk HJ (1962) Emulgators in the digestive fluids of invertebrates. Arc Int Physiol Biochim 70:67-85

Vonk HJ (1969) The properties of some emulsifiers in the digestive fluids of invertebrates. Comp Biochem Physiol 29:361-371

Voparil IM, Mayer LM (2000) Dissolution of sedimentary polycyclic aromatic hydrocarbons into the lugworm's (Arenicola marina) digestive fluids. Environ Sci Technol 34:1221-1228

Weston DP, Mayer LM (1998) Comparison of in vitro digestive fluid extraction and traditional in vivo approaches as measures of polycyclic aromatic hydrocarbon bioavailability from sediments. Environ Toxicol Chem 17:830-840

Submitted: February 4, 2003; Accepted: June 19, 2003

Proofs received from author(s): August 21, 2003 